\title{
Differential Dopamine Release Dynamics in the Nucleus Accumbens Core and Shell Reveal Complementary Signals for Error Prediction and Incentive Motivation
}

\author{
@Michael P. Saddoris, ${ }^{1,2}$ Fabio Cacciapaglia, ${ }^{2,3}$ 으. Mark Wightman, ${ }^{3}$ and Regina M. Carelli ${ }^{2}$ \\ ${ }^{1}$ Department of Psychology and Neuroscience, University of Colorado Boulder, Boulder, Colorado 80309, and Departments of ${ }^{2}$ Psychology and \\ Neuroscience and ${ }^{3}$ Chemistry, University of North Carolina Chapel Hill, North Carolina 27599
}

\begin{abstract}
Mesolimbic dopamine (DA) is phasically released during appetitive behaviors, though there is substantive disagreement about the specific purpose of these DA signals. For example, prediction error (PE) models suggest a role of learning, while incentive salience (IS) models argue that the DA signal imbues stimuli with value and thereby stimulates motivated behavior. However, within the nucleus accumbens (NAc) patterns of DA release can strikingly differ between subregions, and as such, it is possible that these patterns differentially contribute to aspects of PE and IS. To assess this, we measured DA release in subregions of the NAc during a behavioral task that spatiotemporally separated sequential goal-directed stimuli. Electrochemical methods were used to measure subsecond NAc dopamine release in the core and shell during a well learned instrumental chain schedule in which rats were trained to press one lever (seeking; SL) to gain access to a second lever (taking; TL) linked with food delivery, and again during extinction. In the core, phasic DA release was greatest following initial SL presentation, but minimal for the subsequent TL and reward events. In contrast, phasic shell DA showed robust release at all task events. Signaling decreased between the beginning and end of sessions in the shell, but not core. During extinction, peak DA release in the core showed a graded decrease for the SL and pauses in release during omitted expected rewards, whereas shell DA release decreased predominantly during the TL. These release dynamics suggest parallel DA signals capable of supporting distinct theories of appetitive behavior.
\end{abstract}

Key words: associative learning; fast-scan cyclic voltammetry; incentive salience; reinforcement learning; striatum; ventral tegmental area

\section{Significance Statement}

Dopamine signaling in the brain is important for a variety of cognitive functions, such as learning and motivation. Typically, it is assumed that a single dopamine signal is sufficient to support these cognitive functions, though competing theories disagree on how dopamine contributes to reward-based behaviors. Here, we have found that real-time dopamine release within the nucleus accumbens (a primary target of midbrain dopamine neurons) strikingly varies between core and shell subregions. In the core, dopamine dynamics are consistent with learning-based theories (such as reward prediction error) whereas in the shell, dopamine is consistent with motivation-based theories (e.g., incentive salience). These findings demonstrate that dopamine plays multiple and complementary roles based on discrete circuits that help animals optimize rewarding behaviors.

\section{Introduction}

Understanding the role of dopamine (DA) signaling in relation to learning, behavior and addiction is a central issue in behavioral neuroscience. Contemporary theories are consistent with the anatomical organization of the mesolimbic DA system, wherein a

\footnotetext{
Received June 18, 2015; revised July 8, 2015; accepted July 15, 2015.

Author contributions: M.P.S. and F.C. designed research; M.P.S. and F.C. performed research; M.P.S. and F.C analyzed data; M.P.S., R.M.W., and R.M.C. wrote the paper.

This work was supported by National Institutes on Drug Abuse Grants DA028156 and DA035322 to M.P.S. and DA017318 and DA034021 to RMC, and DA010900 to R.M.W. We thank Dr Elizabeth West for comments on an earlier draft of this work.
}

relatively small population of DAergic neurons in the ventral tegmental area (VTA) sends collaterals throughout the brain to broadly modulate circuits for learning and action. However, recent evidence suggests that DA signaling may be more heterogeneous than previously considered. For example, phasic DA release following reward-predictive cues scales with the antici-

The authors declare no competing financial interests.

Correspondence should be addressed to Dr Michael Saddoris, Department of Psychology and Neuroscience, University of Colorado Boulder, Muenzinger, UCB 345, Boulder, C0 80309-0345. E-mail: Michael.Saddoris@colorado.edu. DOI:10.1523/JNEUROSCI.2344-15.2015

Copyright $\odot 2015$ the authors $\quad 0270-6474 / 15 / 3511572-11 \$ 15.00 / 0$ 
pated subjective reward value in the nucleus accumbens (NAc) core, but not shell (Day et al., 2010; Sugam et al., 2012). In contrast, motivational shifts in hedonic processing of drugpredictive tastants are localized to phasic changes in DA release in the NAc shell, but not core (Wheeler et al., 2011). Further, we and others have shown that DA release during learned tasks encoded stimuli differently between core and shell (Aragona et al., 2009; Owesson-White et al., 2009; Badrinarayan et al., 2012; Cacciapaglia et al., 2012). Instead of a global DA signal, then, these findings suggest that DA may be differentially and discretely tuned to specific target regions to support plasticity within defined circuits related to learning, motivation, and action.

However, the precise functions of these heterogeneous DA signals are not well understood. One influential model has posited that DA provides a teaching signal to generate associative expectancies of future outcomes and whether those predictions are accurate [prediction error (PE)]. DA neurons display this type of encoding (Schultz et al., 1997; Schultz and Dickinson, 2000; Waelti et al., 2001; Tobler et al., 2003), although recent findings confirm that essentially all optogenetically identified DA neurons in the VTA show PE-type signaling (Cohen et al., 2012). In contrast, incentive salience (IS) models suggest that DA acts to endow stimuli with valued reinforcers, creating motivational drive for those outcomes (Berridge and Robinson, 1998; Robinson and Berridge, 2008; Zhang et al., 2009; Berridge, 2012). Although similar, PE and IS models make strongly divergent predictions for DA function with respect to its necessity in learning, motivation, and drug addiction (Redish, 2004; Tindell et al., 2009; Bromberg-Martin et al., 2010; Berridge, 2012).

In simple conditioning tasks, it is difficult to know what phasic DA release is encoding (i.e., is it predicting reward, or cue salience?). However, by spatiotemporally isolating predictive and salient stimuli within the same task, it is possible to parse specific features of learning and action to isolate components, such as initial prediction, consummatory behaviors, motivation, and even extinction. To address this, we used an instrumental chain schedule task where presses on one lever [seeking lever (SL)] granted access to presses on a second taking lever (TL), and presses on the TL resulted in food delivery. Further, using fastscan cyclic voltammetry (FSCV) to measure real-time DA release patterns in either the NAc core or shell in well trained rats, we differentiated how task-selective features of DA encoding differed across NAc subregions. Finally, we examined how these signals dynamically shifted when aspects of motivation (hunger level) and prediction (extinction) were altered. We observed differential patterns of DA release in the core and shell that were highly consistent with PE and IS models, respectively, and generally support the idea of multiple mesolimbic DA signals that can support complementary but distinct aspects of goal-directed behavior.

\section{Materials and Methods}

Animals. Twelve male Sprague-Dawley rats weighing 280-330 g were used as subjects. Rats were individually housed with a $12 \mathrm{~h}$ light/dark cycle and lightly food restricted to no less than $90 \%$ free-feed weight (10-15 g of Purina laboratory chow each day, in addition to $\sim 2.7 \mathrm{~g}$ of sucrose consumed during daily sessions). Food restriction was in place for the duration of behavioral testing except during the postsurgery recovery period, when food was given ad libitum. All procedures were performed in accordance with the University of North Carolina at Chapel Hill Institutional Animal Care and Use Committee.

Behavioral training: chain schedule. Testing chambers contained two retractable levers with a cue-light above each lever and a food receptacle positioned equal distance between the levers as previously described
(Cacciapaglia et al., 2012). For each subject, one lever (e.g., left) was designated the TL and the other lever (e.g., right) as the SL for the duration of all test sessions. The side of the TL and SL was counterbalanced across subjects.

Rats were first trained to obtain sucrose pellets (45 mg, Purina) from the food-cup receptacle. During a single pretraining session, 50 pellets were delivered randomly approximately once every $30 \mathrm{~s}$. Rats were then trained to self-administer sucrose pellets during single daily sessions. To shape instrumental responding, animals were first trained to press the TL. Each trial during shaping began with the illumination of a light cue directly above the TL coupled with the extension of the TL into the test chamber[taking lever out $\left.\left(\mathrm{TL}^{\mathrm{O}}\right)\right]$. Each taking lever press $\left[\mathrm{TL}^{\mathrm{P}}\right.$; fixed ratio 1 (FR1)] within $15 \mathrm{~s}$ of extension resulted in the delivery of a single sucrose pellet $(45 \mathrm{mg})$ into the receptacle, retraction of the TL, and termination of the cue light. If animals failed to press the TL within $15 \mathrm{~s}$, the lever was retracted, the cue light extinguished, and the trial counted as an omission. Trials were separated by a variable intertrial interval with an average of $15 \mathrm{~s}$ (range: 5-25 s; shaping days 1 and 2), and then increased to an average of $45 \mathrm{~s}$ on shaping days 3-4 (range: 30-60 s).

After the establishment of stable responding on the TL (i.e., no more than 2 omission errors in a session) the chain schedule was introduced (Fig. 1A), adapted from Olmstead et al. (2000). Trials during chain schedule sessions began with the extension of the SL and the simultaneous illumination of the cue light directly above it $\left(\mathrm{SL}^{\mathrm{O}}\right)$. Each $\mathrm{SL}^{\mathrm{P}}(\mathrm{FR} 1)$ resulted in the retraction of the SL and extinguishing of the cue, followed by presentation of the $\mathrm{TL}^{\mathrm{O}}$ (lever extension, cue light). As above, TL presses resulted in the retraction of the TL, extinguishing of the cue light and the delivery of a sucrose pellet to the food cup. Trials were separated by a variable $45 \mathrm{~s}$ intertrial interval (range: $30-60 \mathrm{~s}$ ), and each session consisted of 30 trials. For day 1 of the chain schedule, there was no delay between retraction of the SL and extension of the TL. On subsequent days, a variable interval (VI) of 3-5 s was introduced between retraction of the SL press and extension of the TL. In addition, a VI 1-3 s was introduced between TL press and the delivery of the sucrose reinforcement. Variable delays were used during training (i.e., all sessions before FSCV recordings) to eliminate the ability for rats to predictively time the delivery of events. Rats were trained for $5 \mathrm{~d}$ on this chain schedule or until they showed stable performance of two consecutive sessions without an omission on either the SL or TL, after which they were surgically prepared for voltammetric recording.

Behavioral training: extinction. After the last recording session, a subset of animals underwent extinction (core recordings: $n=3$; shell recordings: $n=7$ ). During extinction, $\mathrm{SL}^{\mathrm{O}}$ presentations indicated the beginning of a new trial. Trials were identical to those in the test session, where SL presses resulted in presentations of the $\mathrm{TL}^{\mathrm{O}} 4 \mathrm{~s}$ later, but presses on the TL were not reinforced. Extinction sessions continued until rats stopped responding on the SL for 10 consecutive trials (Fig. 1B).

Previous studies (Schoenbaum et al., 2003; Saddoris et al., 2005) have shown that neural correlates of limbic activity are highly sensitive to changes in learning and motivational state, and thus here we used response latency markers to define blocks for each subject (Fig. 1B). The first block was early extinction, in which response latency for an $\mathrm{SL}^{\mathrm{P}}$ response was similar to the rewarded session. Next, the first $\mathrm{SL}^{\mathrm{P}}$ response latency that was at least $2 \mathrm{SD}$ longer than during the previously rewarded chain session marked the beginning of Delay Extinction. Finally, all trials that followed the first omitted response were in the late extinction block, and were grouped by whether the rat omitted a $\mathrm{SL}^{\mathrm{P}}$ response (late no press) or resumed responding (late press). All extinction behavior was compared with the immediately preceding reinforced chain schedule.

Surgical procedures. After behavioral training, animals were surgically prepared for voltammetric recordings as previously described (Cacciapaglia et al., 2012). Briefly, rats were anesthetized with an intramuscular injection of ketamine hydrochloride $(100 \mathrm{mg} / \mathrm{kg}$, i.m.) and xylazine hydrochloride $(20 \mathrm{mg} / \mathrm{kg})$ mix. A guide cannula (Bioanalytical Systems) was implanted above either the NAc shell $(+1.7 \mathrm{~mm} \mathrm{AP},+0.8 \mathrm{~mm} \mathrm{ML})$ or core ( $+1.3 \mathrm{~mm} \mathrm{AP},+1.3 \mathrm{~mm} \mathrm{ML})$ and a bipolar stimulating electrode (Plastics One) was placed in the VTA $(-5.2 \mathrm{~mm} \mathrm{AP},+1.0 \mathrm{~mm} \mathrm{ML}$ and $-7.8 \mathrm{DV})$. Another guide cannula for the reference $\mathrm{Ag} / \mathrm{AgCl}$ electrode 
A

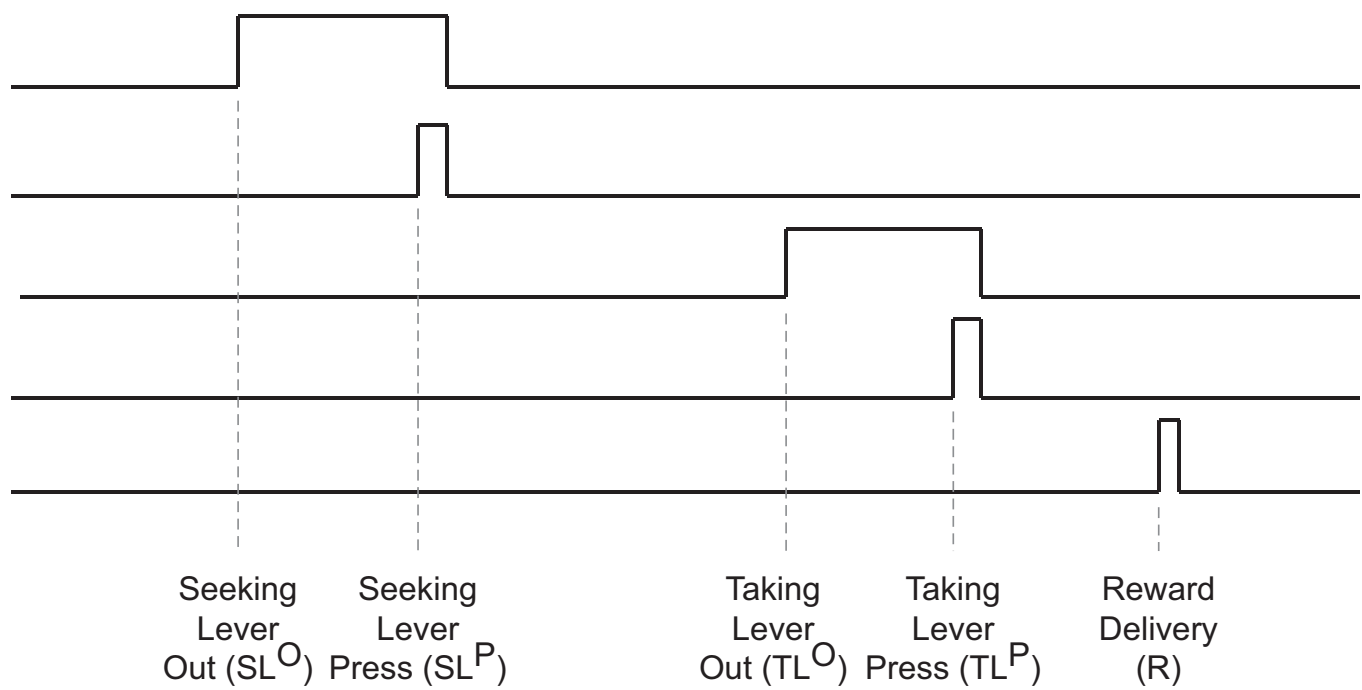

B

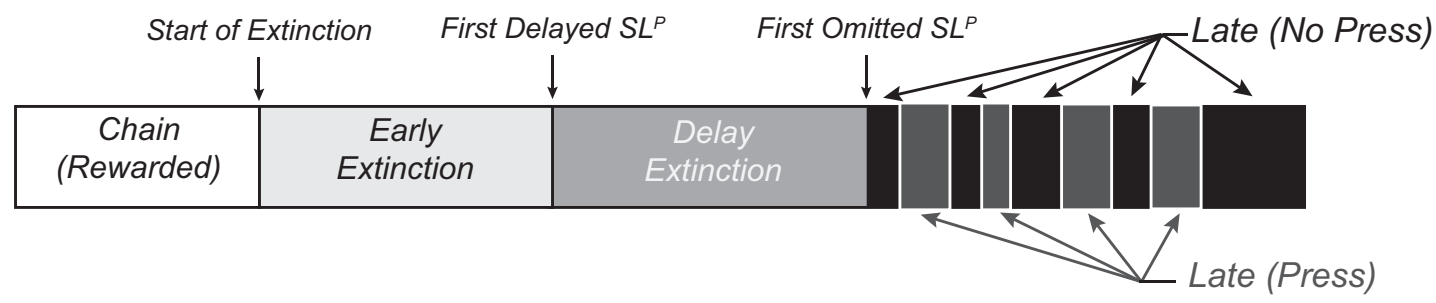

C
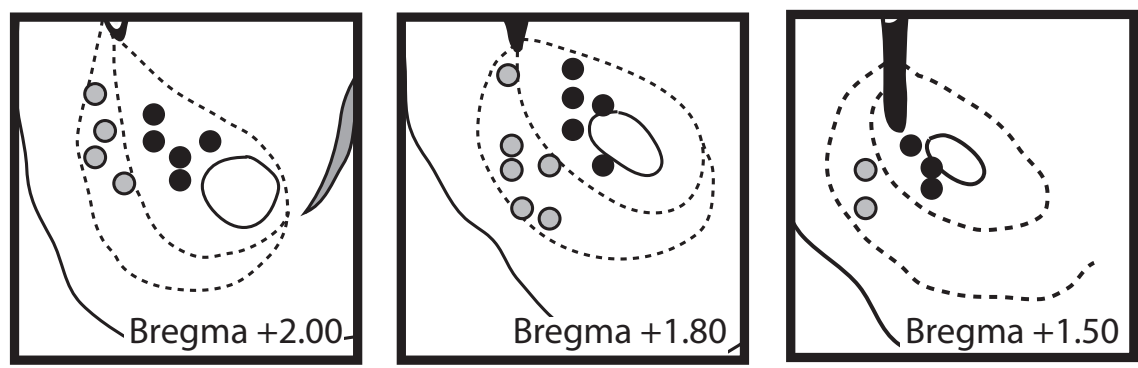

Figure 1. A, Schematic of task design. During the chain schedule, one lever (SL) was extended into the test chamber at the same time as a cue light was illuminated above the lever (SL ${ }^{0}$ ). $S L^{P}$ extinguished the light and retracted the lever. After a delay, the other lever in the chamber (TL) was extended and associated cue light illuminated $\left(\mathrm{TL}^{0}\right)$. Following a press on the $\mathrm{TL}\left(\mathrm{TL}^{\mathrm{P}}\right)$ rats received food reinforcement after a delay (R). B, Extinction behavior in animals with FSCV recordings in the core or shell. Behavior and analysis in extinction was grouped by block based on the rat's behavior. Trials in the immediate preceding chain task were used to compare events in extinction. Early extinction was all trials until the first significantly delay response on the SL, whereas delay extinction was all trials between the first delayed $\mathrm{SL}^{\mathrm{P}}$ and the first omitted press following $\mathrm{SL}^{0}$ presentation. Within the late extinction block, distinctions were made between whether the subject made a press or omitted a response. $C$, Histology of electrode placements within the core (black circles) and medial shell (gray circles).

was placed in the contralateral hemisphere. Components were secured to the skull with screws and cranioplastic cement.

Voltammetric recording. FSCV recording techniques used here were as described in detail previously (Cacciapaglia et al., 2012; Sugam et al., 2012). Briefly, after surgery, rats were allowed to recover to their presurgery body weight (at least $5 \mathrm{~d}$ of recovery). The day of the experiment, a carbon-fiber microelectrode was lowered into the NAc shell or core with a locally constructed microdrive (Chemistry Department Electronic Facility, University of North Carolina, Chapel Hill, NC), after placing an $\mathrm{Ag} / \mathrm{AgCl}$ reference electrode in the contralateral hemisphere. The carbon-fiber microelectrode was held at $-0.4 \mathrm{~V}$ versus $\mathrm{Ag} / \mathrm{AgCl}$ reference electrode. Periodically a cyclic voltammogram was acquired (100 $\mathrm{ms}$ intervals) by applying a triangular waveform that drove the potential to $1.3 \mathrm{~V}$ and back to $-0.4 \mathrm{~V}$. Before the start of each recording session, we obtained electrically evoked DA release events by driving the bipolar stimulating electrode in the VTA and recorded the resultant DA release in the NAc. If a stimulation was unsuccessful at eliciting DA release, the electrode was lowered to a new location and the process was repeated. Once electrical stimulation successfully evoked DA release in the NAc, a training set of evoked DA release was created using a combination of stimulating frequencies (between 10 and $60 \mathrm{~Hz}$ ) and number of biphasic pulses (from 4 to 25) from the bipolar VTA electrode. In a subset of recordings, an additional training set was created following the end of the behavioral session to ensure electrode stability over the session. In a subset of rats $(n=9)$, after recording a full session of 30 trials, the electrode was lowered another $\sim 300 \mu \mathrm{m}$ until another release site was 
found, at which point another recording was taken for another session of 30 trials. Analysis of the FSCV data (HDCV Analysis) used chemometric principal component analysis to extract changes in current due to DA using each subject's electrically stimulated training set from the related recording session collected before testing, as previously described (Heien et al., 2005; Keithley et al., 2010). For each region (core and shell), an average DA concentration trace was aligned to each behavioral event and compared with the average DA concentration over a $5 \mathrm{~s}$ baseline immediately before $\mathrm{SL}^{\mathrm{O}}$ onset using a two-way mixed model ANOVA (factors: event, region) on subject averages.

For extinction sessions, DA traces were likewise aligned to the behavioral events. However, because many $\mathrm{SL}^{\mathrm{O}}$ presentations were not followed by any presses in extinction, two different analyses were used. For the first, DA traces were aligned to $\mathrm{SL}^{\mathrm{O}}$ and grouped by phase of extinction (see Fig. 6), and analyzed using a two-way repeated measures using extinction phase and stimulus event as factors. For the second analysis, only trials in which the rat pressed the $\mathrm{TL}^{\mathrm{P}}$ were used and peak DA concentrations (i.e., maximum DA release within $300 \mathrm{~ms}$ following the event) were obtained for both $\mathrm{TL}^{\mathrm{P}}$ and reward, and likewise analyzed with a two-way repeated-measures ANOVA using extinction phase and task stimulus as factors. All post hoc pairwise comparisons were made using Tukey's HSD, corrected for unequal $N$ when appropriate. All statistical analyses were performed using Prism 4.0 for Windows (GraphPad Software) or Statistica for Windows (StatSoft).

Histology. After each experiment, rats were deeply anesthetized with a ketamine (100 mg/kg)/xylazine (20 mg/kg) mixture (i.m.). A tungsten electrode housed in the same micromanipulator used during the experiment was lowered to the experimental recording site and a small electrolytic lesion was made $(50-500 \mu \mathrm{A}, 5 \mathrm{~s})$ to mark the position of the electrode tip. Multiple lesions where made when multiple recordings had been done. Each brain was removed, fixed in $4 \%$ formaldehyde, and then frozen to $-80 \mathrm{C}$ before being sliced into $40 \mu \mathrm{m}$ coronal sections with a cryostat. Sections were mounted on slides, viewed with bright-field microscopy and digitally imaged (Fig. 1C).

Comparison of stimulated and event-evoked DA release in core and shell. It was possible that the differences seen between core and shell DA release for behavioral events was due not to differences in release dynamics, but rather to differences in the kinetics of DA clearance between the regions. For example, striatal DA release and uptake dynamics is slower in the shell than the core due a lower density of the dopamine transporter in the shell (Jones et al., 1996; Budygin et al., 2002). As such, differences between core and shell at later events (e.g., $\mathrm{TL}^{\mathrm{O}}$, reward) could be explained by the persistence of residual DA in the synaptic region in the shell.

To address this concern, we compared DA release and uptake patterns elicited by behavioral events (i.e., $\mathrm{SL}^{\mathrm{O}}$ ) during the chain schedule task to DA elicited by a brief burst of electrical stimulation of VTA afferents. Originally, electrical stimulation ( $2 \mathrm{~ms}$ biphasic pulses) of VTA fibers was conducted across a wide array of stimulation frequencies $(10-60 \mathrm{~Hz})$ and pulse numbers $(4-25$ pulses $)$ to obtain a full spectrum of release dynamics for purposes of building a chemometric training set. As such, a large number of electrical stimulations were substantially greater (e.g., $2000 \mathrm{~nm}$ ) than seen in naturally occurring transients (typically $40-150 \mathrm{nM}$ ). At extremely large concentrations of DA release, it is possible that the DA transporter can become saturated, leading to slower clearance kinetics than would be seen in the normal range. To address this directly, we selected only electrical stimulation "trials" in which the peak DA release was $<200 \mathrm{~nm}$. Likewise, we selected only behavioral trials where the peak DA release aligned to the $\mathrm{SL}^{\mathrm{O}}$ was at least $100 \mathrm{~nm}$. For each subject, all eligible trials were averaged for analysis. Using this metric, we obtained 23 electrical stimulations and 15 cue-evoked sessions in the core, and 14 electrical stimulations and 11 cue-evoked sessions in the shell.

Comparisons of cue- versus electrically-evoked DA release were done using several metrics. First, peak DA was derived from the behavioral events at $\mathrm{SL}^{\mathrm{O}}$ (i.e., greatest DA concentration within $1.5 \mathrm{~s} \mathrm{SL}^{\mathrm{O}}$ onset), $\mathrm{TL}^{\mathrm{O}}$ (greatest DA concentration between 4 and $5.5 \mathrm{~s}$ following $\mathrm{SL}^{\mathrm{O}}$ onset) and reward (greatest DA concentration between $6.5-8 \mathrm{~s}$ following $\mathrm{SL}^{\mathrm{O}}$ onset) for cue events, and at the corresponding time points for electrically stimulated events (i.e., same time points, but following stim- ulation onset rather than $\mathrm{SL}^{\mathrm{O}}$ onset). Next, clearance dynamics were examined using previously published metrics (Yorgason et al., 2011). Specifically, we looked at latency to half-life (concentration half of peak concentration) following peak, $T_{20}$ (the time for $20 \%$ decay from peak) and $T_{80}$ (time for $80 \%$ decay from peak). These values were compared using a mixed-model ANOVA using region (core, shell), stimulation type ( $\mathrm{SL}^{\mathrm{O}}$ aligned, electrically stimulated) as between-subjects factors and either DA concentration at each event type (baseline, $\mathrm{SL}^{\mathrm{O}}, \mathrm{TL}^{\mathrm{O}}$, and reward) or decay measure (latencies to peak, $T_{20}$, half-life, and $T_{80}$, respectively) as repeated measures. Post hoc comparisons were done using Tukey's HSD for unequal $N$.

\section{Results}

\section{Reinforced chain schedule behavior}

Rats rapidly learned the chain schedule task. On the final presurgery session, rats on average completed $99.8 \%$ of the trials accurately. During those sessions, rats took on average $783 \pm 253 \mathrm{~ms}$ to press following $\mathrm{SL}^{\mathrm{O}}$, and $588 \pm 298 \mathrm{~ms}$ to press after $\mathrm{TL}^{\mathrm{O}}$, a difference that was nearly significant, $t_{(17)}=1.77, p=0.085$ However, on postsurgical recording days, rats again made almost no omissions (99.5\%), but displayed significantly faster response latencies for $\mathrm{TL}^{\mathrm{P}}(999 \pm 64 \mathrm{~ms})$ than $\mathrm{SL}^{\mathrm{P}}(444 \pm 39 \mathrm{~ms}), t_{(29)}=$ $7.48, p<0.0001$. Importantly, on the days of recording, there were no differences in response latency for animals recorded in the shell versus core, $t_{(29)}=0.78, p=0.48$. Thus, rats in both groups (core and shell) were equally competent to complete the chain schedule when the task was reinforced.

\section{Differential DA release in NAc core and shell during reinforced chain schedule}

Next, we used FSCV to obtain real-time DA recordings from either the NAc core $(n=13)$ or shell $(n=12)$ during performance on the well learned chain schedule (Fig. $1 C$ ). In rats where multiple recordings were taken, the electrode tip was lowered at least $300 \mu \mathrm{m}$ between sessions to ensure that the $100 \mu \mathrm{m}$ carbonfiber electrode tip was entirely in fresh tissue for each recording. Consistent with both $P E$ and IS models, we found robust phasic DA release that began with the onset of the SL and cue light $\left(\mathrm{SL}^{\mathrm{O}}\right)$ in both core and shell. Examples of this signaling from representative recording sessions (averaged across 30 trials) are shown for the core (Fig. 2A) and shell (Fig. 2B), with color plots from an individual animal. DA signaling differed strikingly between subregions. Across all rats, in the core (Fig. 2C-E, black traces), DA peaked rapidly at the onset of the most predictive cue ( $\mathrm{SL}^{\mathrm{O}}$ onset) and then quickly declined to baseline by the time of the $\mathrm{TL}^{\mathrm{P}}$. In contrast, in the shell (Fig. 2C-E, gray traces), rapid increases in DA concentration were coincident with $\mathrm{SL}^{\mathrm{O}}$ presentation and remained elevated for other motivationally salient stimuli with discrete peaks at $\mathrm{TL}^{\mathrm{O}}$ and reward delivery before returning to baseline at the end of the trial.

We quantified these observations by averaging all recordings taken in either the core or shell, aligned to each of the behavioral events in the chain schedule (Fig. 2C-H). In the FSCV recording sessions, the time between $\mathrm{SL}^{\mathrm{P}}$ and $\mathrm{TL}^{\mathrm{O}}$ was fixed $(4 \mathrm{~s})$ as was the time between $\mathrm{TL}^{\mathrm{P}}$ and reward delivery (2.5 s) to allow for better alignment of task stimuli for DA analysis. Thus, aligning to $\mathrm{SL}^{\mathrm{O}}, \mathrm{SL}^{\mathrm{P}} / \mathrm{TL}^{\mathrm{O}}$, and $\mathrm{TL}^{\mathrm{P}} /$ reward allowed alignment of all behavioral markers and permitted analysis of peak DA release relative to these events.

A two-way ANOVA comparing peak (maximum DA concentration within $300 \mathrm{~ms}$ following event) DA concentrations across region (core, shell) and event (baseline, $\mathrm{SL}^{\mathrm{O}}, \mathrm{SL}^{\mathrm{P}}, \mathrm{TL}^{\mathrm{O}}$, $\mathrm{TL}^{\mathrm{P}}$, reward) indicated that the shell released more DA overall than the core, $F_{(1,24)}=13.63, p<0.002$. Importantly, a sig- 
A

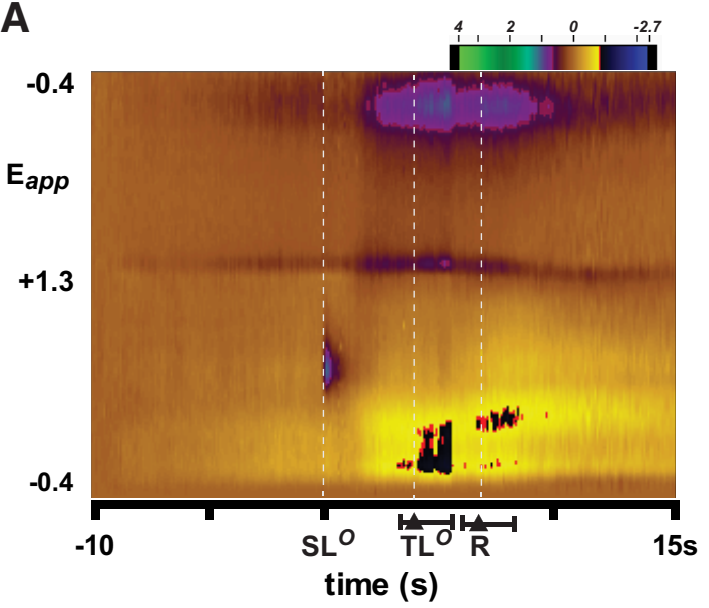

B

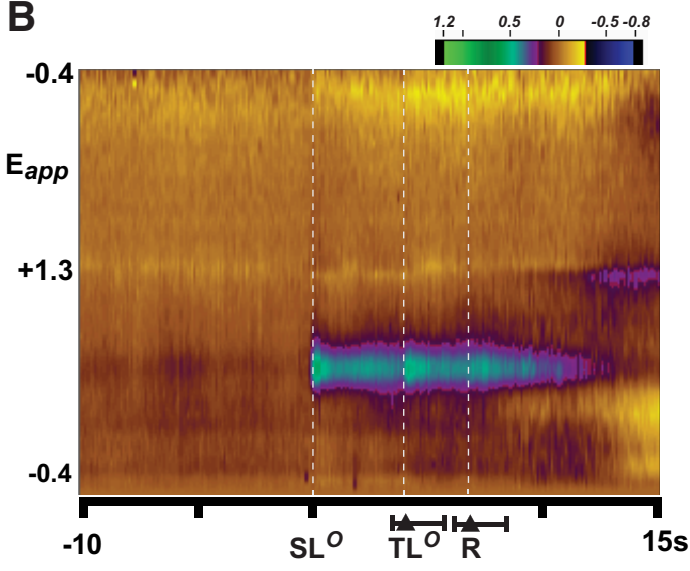

C

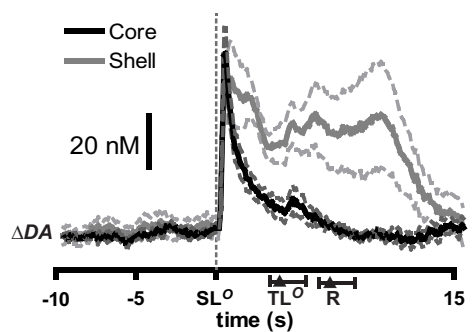

F

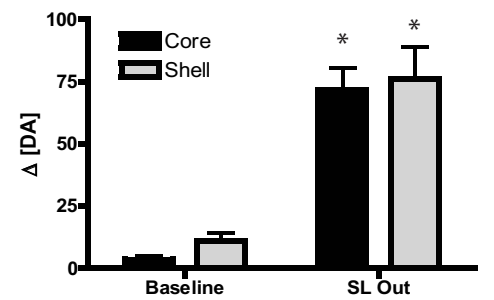

D

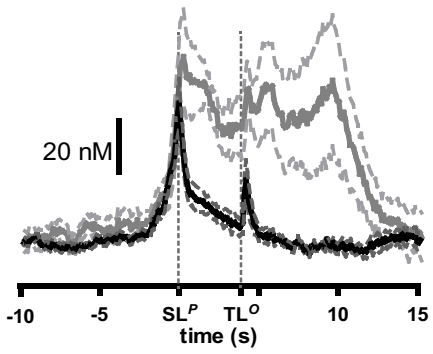

G

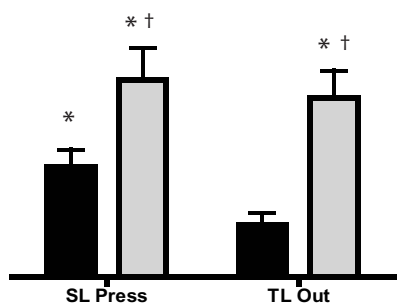

E

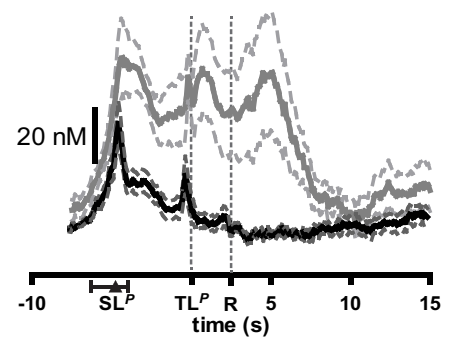

H

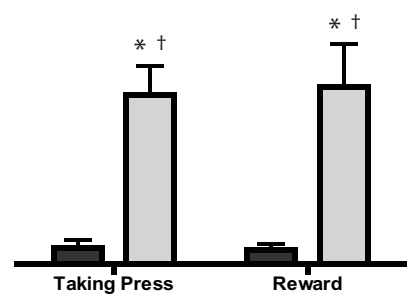

Figure 2. Performance of the chained schedule produced different DA release dynamics within the NAc. Dopamine release dynamics in the core $(\boldsymbol{A})$ and shell $(\boldsymbol{B})$ of the NAc aligned to the time of $S L$ extension into the chamber $\left(S L^{0}\right)$. Color plots each show averages from a representative subject in the core and shell, respectively. Average time $\left(\mathbf{( \Lambda )}\right.$ of the $T L$ extension $\left(T L{ }^{0}\right)$ and reward $(R)$ and range $( \pm 2 S D)$ relative to $S L^{0}$ are shown at bottom. $\boldsymbol{C}-\boldsymbol{E}$, Across-subject mean DA release across all recordings in core (black) and shell (gray) relative to $(\boldsymbol{C}) \mathrm{SL}^{0},(\boldsymbol{D}) \mathrm{SL}^{\mathrm{P}}$, and the extension of the $\mathrm{TL}^{0} 4 \mathrm{~s}$ later, and $(\boldsymbol{E}) \mathrm{TL}^{\mathrm{P}}$, and the reward $(\mathrm{R})$ food pellet delivered $2.5 \mathrm{~s}$ after press. Dashed line shows SEM of the average for each region. Bottom row $(\boldsymbol{F}-\boldsymbol{H})$ shows average peak DA release for each behavioral event. ${ }^{*} p<0.05$ versus baseline; $\nmid p<0.05$ core versus shell.

nificant interaction of region $\times$ event, $F_{(5,120)}=9.88, p<$ 0.0001 , revealed that DA signaling in the core and shell differentially responded to the behavioral events (Fig. $2 F-H$ ). Specifically, core DA release significantly increased at $\mathrm{SL}^{\mathrm{O}}$, relative to baseline $(p<0.0001)$, and remained above baseline at the time of $\mathrm{SL}^{\mathrm{P}}(p<0.0001)$, though significantly below that at $\mathrm{SL}^{\mathrm{O}}(p<0.05)$. However, there were no differences in peak DA in the core compared with baseline for either TL event ( $\mathrm{TL}^{\mathrm{O}}$ vs baseline, $p=0.59 ; \mathrm{TL}^{\mathrm{P}}$ vs baseline, $p=1.0$ ), and no difference from baseline at the time of reward receipt $(p=1.0)$.

In contrast, peak DA concentrations in the shell showed significant DA release for all the events. All events were associated with greater DA release than baseline (all comparisons vs BL, $p<$ 0.0002 ), whereas none of the events were significantly different from each other (all pairwise $\mathrm{SL}^{\mathrm{O}}, \mathrm{SL}^{\mathrm{P}}, \mathrm{TL}^{\mathrm{O}}, \mathrm{TL}^{\mathrm{P}}$, and reward comparisons, $p>0.96)$.
Directly comparing core and shell, we found important differences in DA signaling between regions. Although there were no differences in DA release during either baseline $(p=1.0)$ or the SL events $\left(\mathrm{SL}^{\mathrm{O}}, p=1.0 ; \mathrm{SL}^{\mathrm{P}}, p=0.22\right)$, shell DA was significantly elevated compared with core for both TL events $\left(\mathrm{TL}^{\mathrm{O}}, p<0.01\right.$; $\left.\mathrm{TL}^{\mathrm{P}}, p<0.001\right)$ and reward $(p<0.0005$; Fig. $3 D-F)$.

\section{Region-specific changes in DA release between start and end} of session

Next, we compared DA release in the core and shell during the reinforced chain schedule task at the beginning of the session (first 5 trials) versus the end of the session (last 5 trials; Fig. 3 ). This was important to test to ensure that the electrode was stable throughout the session (i.e., that the electrode did not lose sensitivity over time), and also to assess whether DA tracks any subtle changes in motivational state (for example, 
A

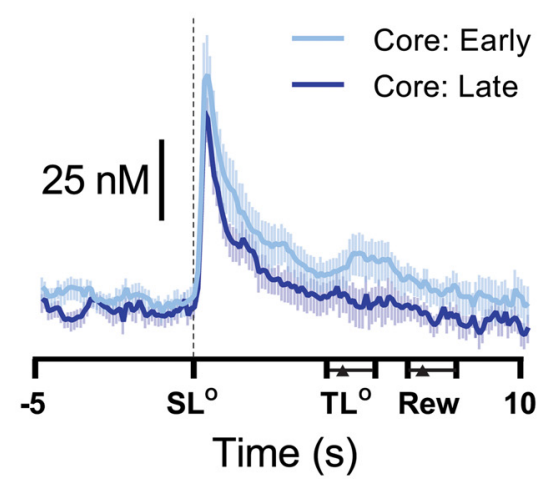

C

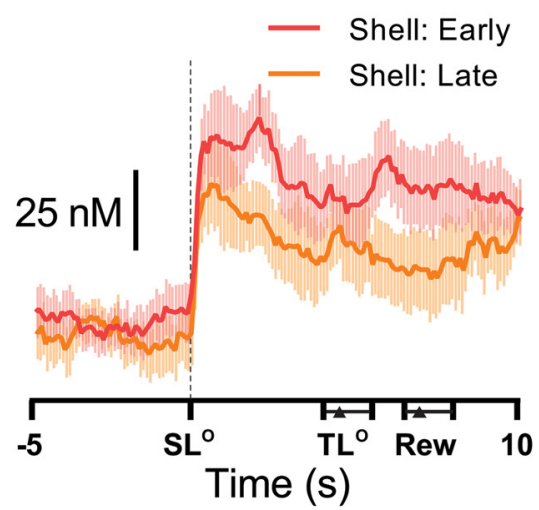

B

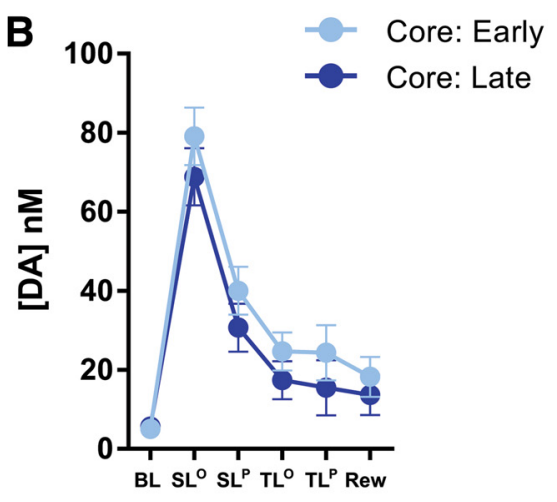

D

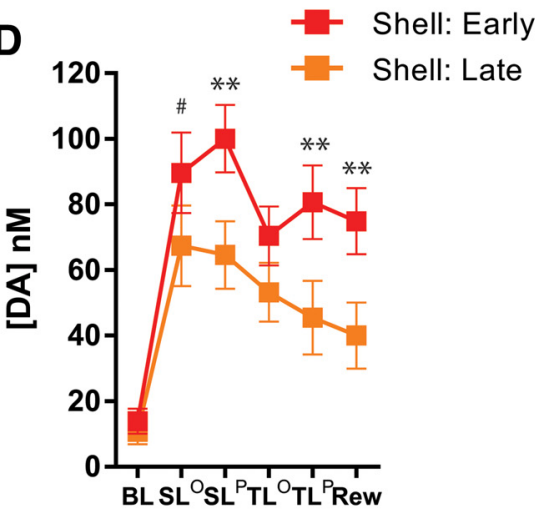

Figure 3. Changes in DA signaling between the beginning of the session (early; first 5 trials of the chain schedule) versus the end of the session (late; last 5 trials). $A$, Average DA concentrations in the NAc core from the averages of each subject's first five trials (light blue) and last five trials (purple). $\boldsymbol{B}$, In the core, within-subjects peak DA signaling was unchanged between the beginning of the session and end. C, Average DA concentrations in the NAc shell from the averages of each subject's first five trials (red) and last five trials (orange). D, Shell DA showed a significant within-subjects decrease at both the $S L^{P}$ and $\mathrm{TL}^{\mathrm{P}}$ cues and reward $\left({ }^{* *} p<\right.$ 0.01 ), whereas the decrease at the $S L^{0}$ cue was nearly significant (\#p=0.073). Error bars show SE of the difference (early vs late).

due to any effects of decreased hunger after consuming the food) following presentation of the different stimuli.

In the core (Fig. $3 A$ ), a two-way ANOVA indicated a significant main effect of event $\left(\mathrm{BL}, \mathrm{SL}^{\mathrm{O}}, \mathrm{SL}^{\mathrm{P}}, \mathrm{TL}^{\mathrm{O}}, \mathrm{TL}^{\mathrm{P}}\right.$, Rew; $F_{(5,65)}$ $=35.03, p<0.0001$ ), but no effect of session phase (early vs late; $\left.F_{(1,13)}=3.55, p=0.08\right)$, or interaction between event $\times$ session phase $\left(F_{(5,65)}=0.82, p=0.54\right)$. Post hoc comparisons between early and late blocks indicated that peak DA release relative to the behavioral events in the core remained the same between the beginning and end of the session (Tukey: all early vs late pairwise comparisons for $\mathrm{BL}, \mathrm{SL}^{\mathrm{O}}, \mathrm{SL}^{\mathrm{P}}, \mathrm{TL}^{\mathrm{O}}, \mathrm{TL}^{\mathrm{P}}$, and reward, $p>0.50$; Fig. $3 B$ ).

However, phasic DA release to task stimuli generally decreased over the session in the shell (Fig. 3C,D), with significant main effects of event $\left(F_{(5,55)}=13.52, p<0.0001\right)$, session phase $\left(F_{(1,11)}=6.95, p=0.02\right)$, and an interaction between event and session phase $\left(F_{(5,55)}=3.74, p=0.006\right)$. As in the core, post hoc tests indicated no difference at BL, but significant decreases in peak DA release to the $\mathrm{SL}^{\mathrm{P}}, \mathrm{TL}^{\mathrm{P}}$, and reward (Tukey: all $p<$ $0.0005)$, a trend toward significance at the $\mathrm{SL}^{\mathrm{O}}$ cue $(p=0.060)$, but no difference at the TL ${ }^{\mathrm{O}}$ cue $(p=0.36)$. Thus, changes in shell (but not core) were limited primarily to motivated actions and reward consumption with differential (albeit modest) effects cue onsets. These across-session shifts in DA release were not because of generalized changes in electrode sensitivity but in- stead suggest that stimulus- and shellspecific changes in DA release patterns indicate information about the altered significance of task stimuli across repeated trials. Given that animals had consumed at least 25 pellets on average by the end of each recording session (i.e., $1144 \mathrm{mg}$, or $7.6 \%$ of the weight of the rats' daily food-restricted regimen), these findings suggest that increased ingestion of the food successfully reduced the motivated hunger state in the animal, which was manifest in changes in the shell but not the core over the course of the session.

\section{Cue-evoked versus electrically stimulated DA dynamics in core and shell}

One caveat to these findings may be that the core and shell have different DA clearance dynamics due to lower density of DA transporter in the shell compared with the core (Jones et al., 1996; Budygin et al., 2002). Thus, it is possible that shell DA seen at TL and reward events is due to residual DA release at the time of $\mathrm{SL}^{\mathrm{O}}$, but is unable to be cleared from synaptic overflow as efficiently as in the core. To address this, we compared electrically stimulated DA release at the same electrode location as during the chain schedule recordings to see whether electrically stimulated dynamics matched cue-evoked dynamics in the core and shell (Fig. 4A). We predicted that if the slower clearance kinetics in the shell were responsible for the differences in subsequent event signaling (e.g., $\mathrm{TL}^{\mathrm{O}}$ ) between the core and shell, then electrically stimulated and cue-evoked release in their respective subregions should follow nearly identical patterns of release and clearance. In contrast, significant deviations from electrical stimulations would suggest that the DA release in that area is tracking task-related events in a manner that cannot be explained by synaptic clearance dynamics alone.

Overall, we found that core and shell sharply differed in their relationship between cue-evoked and electrically evoked DA release (Fig. 4B). Looking at peak concentrations at task events, there were significant differences in DA concentrations as an interaction of region (core/shell) $\times$ stimulation type (electrical versus cue $) \times$ event $\left(\mathrm{BL}, \mathrm{SL}^{\mathrm{O}}, \mathrm{TL}^{\mathrm{O}}, \mathrm{Rew} ; F_{(3,174)}=\right.$ $12.31, p<0.0001)$. In the core, peak DA concentrations for cue-evoked and electrically stimulated traces were nearly identical; there were no statistical differences between these stimulation types at baseline, $\mathrm{SL}^{\mathrm{O}}, \mathrm{TL}^{\mathrm{O}}$, or reward epochs (Tukey: all $p>0.80$ ). In contrast, the shell showed a different pattern of dynamics between electrically- and cue-evoked DA release patterns. Though there was no difference in concentration at baseline or $\mathrm{SL}^{\mathrm{O}}$ (Tukey: both $p>0.98$ ), DA was significantly greater for the $\mathrm{TL}^{\mathrm{O}}$ and reward epochs in the cued trials compared with the electrical stimulations (both $p<$ $0.0001)$. 
A

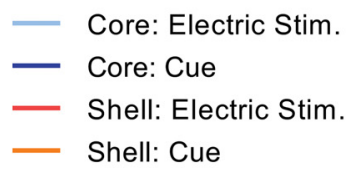

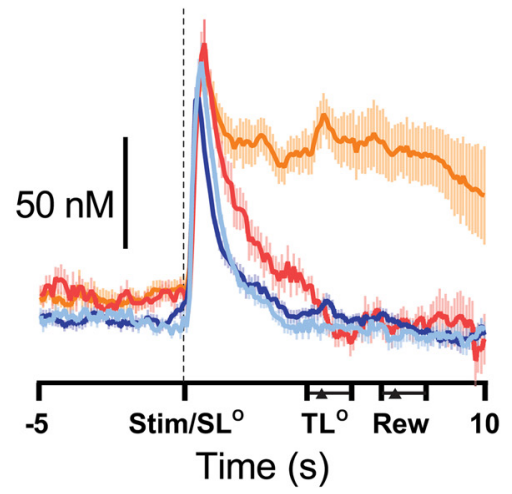

B

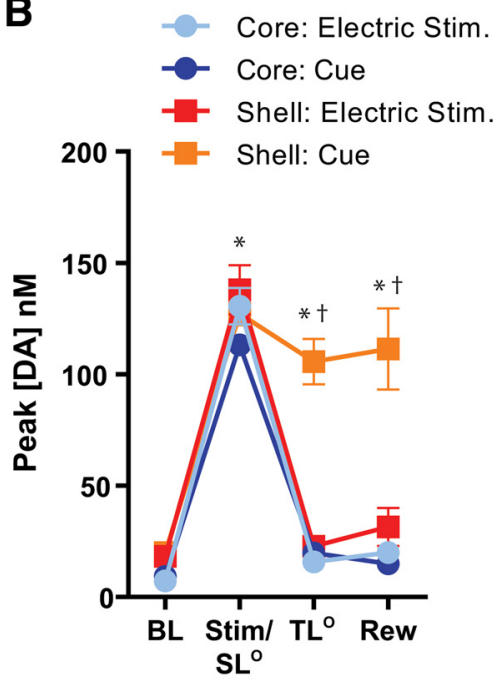

C

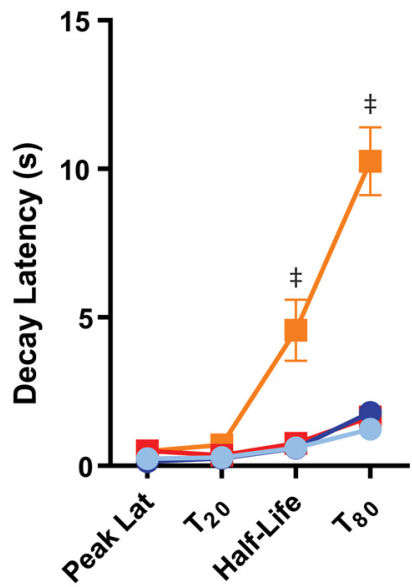

Figure 4. Comparison of electrically stimulated versus cue-evoked DA signaling in the NAc core and shell. $A$, Average concentration of DA aligned to either the $S L^{0}$ cue or electrical stimulation of VTA fiber onset. The timing of the onset of the $\mathrm{TL}^{0}$ cue and reward was estimated on a range of response times for those outcomes following SL ${ }^{\circ}$ (mean response time indicated by triangle; width indicates $\pm 95 \%$ confidence interval). $B$, Comparison of average baseline (BL) DA concentrations to peak DA concentration within $1 \mathrm{~s} \mathrm{of} \mathrm{SL}{ }^{0}$ or electrical stimulation (Stim/SL ${ }^{0}$ ), and within the $95 \%$ confidence interval range for the times corresponding to the $\mathrm{TL}^{0}$ or reward epochs. C, Latency to peak concentration following $\mathrm{SL}^{0}$ or electrical stimulation (Peak Lat) and subsequent decay (clearance) following release in the core and shell. $\mathrm{T}_{20}$ and $\mathrm{T}_{80}$ are the times at which the signal has decayed $20 \%$ and $80 \%$ away from peak, respectively, whereas half-life is the latency following peak to the reach half-peak concentration. ${ }^{*} p<0.0001$, electrical stimulation $/ \mathrm{SL}{ }^{0}$ versus baseline; $t p<0.0001$, Shell: Cue greater [DA] than all other stimulation types; $\neq p<0.0001$, Shell: Cue greater latency to decay from peak than all other stimulation types. Error bars show SE of the difference (cue vs electric).

Likewise, the rate of release and subsequent clearance from the synapse showed a similar pattern (Fig. 4C). Looking at clearance rates as a function of decay from peak, there was a significant interaction between region $\times$ stimulation type $\times$ decay parameter (peak time, $\mathrm{T}_{20}$, half-life, $\mathrm{T}_{80} ; F_{(3,174)}=80.23$, $p<0.00001)$. As above, core clearance and decay dynamics did not differ between cue-evoked and electrically evoked stimulation types. The latency to peak, $T_{20}$, half-life, and $T_{80}$ were all statistically similar regardless of stimulation type (electrical vs cue; all $p>0.95$ ). In contrast, DA levels in the shell showed significantly delayed decay to baseline following $\mathrm{SL}^{\mathrm{O}}$ presentations relative to electrically stimulated trials. While latency to peak and $T_{20}$ were similar between cue-evoked and electricallyevoked stimulations $(p>0.98)$, latency to half-life $(p<0.0001)$, and $T_{80}(p<0.0001)$ were significantly delayed in the cued trials relative to the electrical stimulation. Collectively, these findings demonstrate that intrinsic differences in clearance kinetics in the shell and core are insufficient to explain differences in DA signaling during behavioral performance.

\section{Extinction behavior}

Rats displayed extinction behavior during sessions when the food reward was omitted by progressively increasing the latency to press the different levers over the course of the extinction session. We generated behaviorally defined phases based on these latency shifts relative to press latency on the SL and TL during the imme-
B

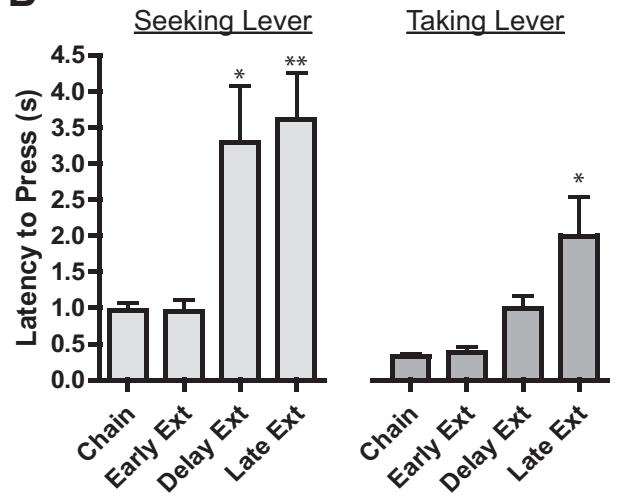

Figure 5. Extinction behavior in animals with FSCV recordings in the core or shell. $\boldsymbol{A}$, The number of trials before rats first showed a significant increase in response latency to shift from the early to delay phase of extinction (left) and response omission (right) for the SL (light gray) and TL (dark gray). Rats showed a latency shift for the TL in significantly fewer trials than the SL, though the number of trials before a trial was omitted was the same between seeking and taking responses. * $p<0.05 \mathrm{SL}$ versus TL. $\boldsymbol{B}$, Response latency to respond on the SL (left) and the TL (right) across phases of extinction. Response latency increased across blocks, and was significantly longer in the delay and late extinction blocks for the SL presses. Presses on the TL were reliably faster than those on the SL within each block. ${ }^{*} p<0.05,{ }^{* *} p<0.01$ vs early Ext.

diately preceding reinforced chain session. The Early phase was defined as the trials where latencies were the same as during the reinforced session. When the rats pressed the lever significantly slower (i.e., $>2 \mathrm{SD}$ ) than normal, this was termed the delay phase which lasted from the first delayed response until the subject omitted a response. All trials after this first omission were termed late phase based on whether the rat pressed (late press) or omitted a response (late no press).

First, we assessed the number of trials performed before the rats exhibited a latency shift from early to delay phase, as well as the number of trials to the first omitted trial (i.e., shift to late phase) for the SL and TL, respectively (Fig. $5 A$ ). Rats slowed responding on the TL significantly before they did so for the SL, paired $t$ test: $t_{(7)}=2.49$, 
A
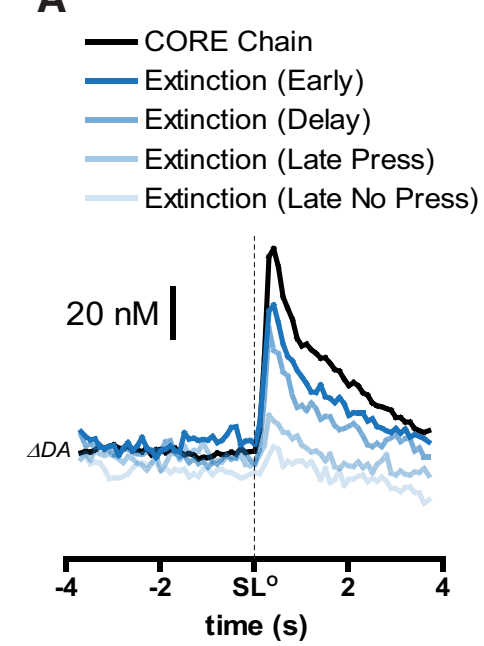

D
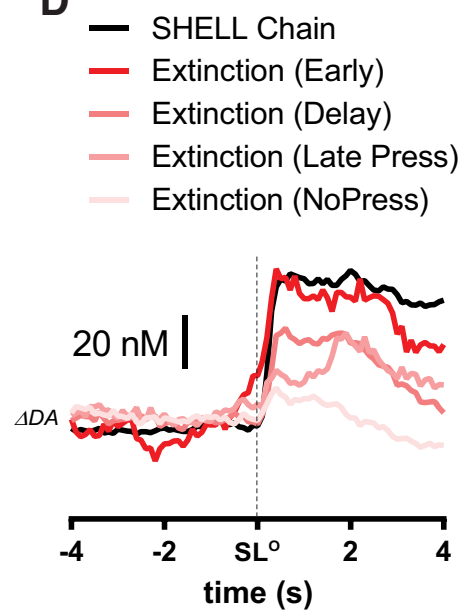

B

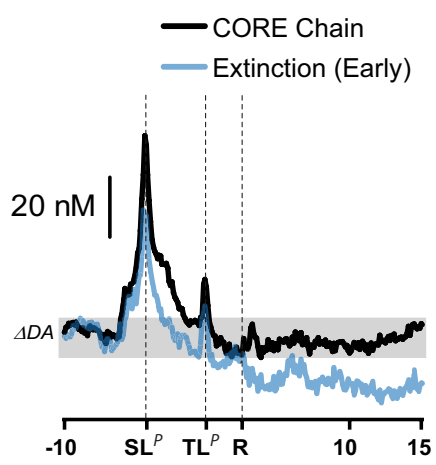

E

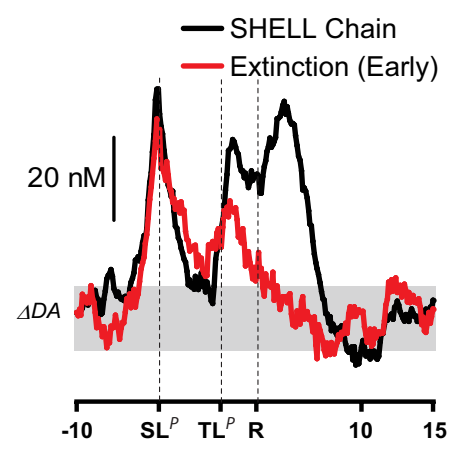

C

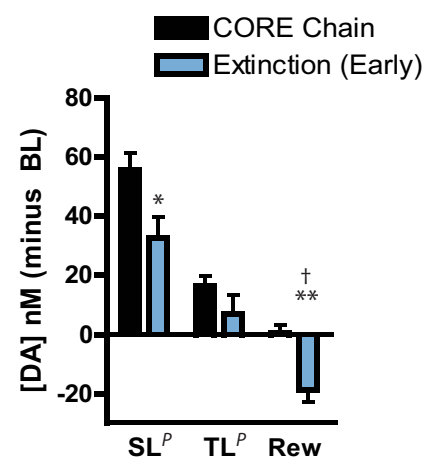

$\mathbf{F}$

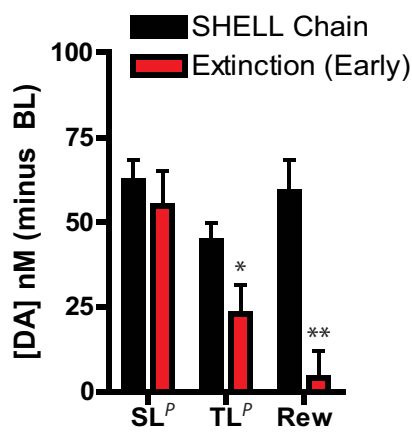

Figure 6. DA release in the core $(\boldsymbol{A}-\boldsymbol{C})$ and shell $(\boldsymbol{D}-\boldsymbol{F})$ during extinction. $\boldsymbol{A}$, Alignment to the $S \mathrm{~L}^{0}$ in the core revealed a continuous decrease in core $\mathrm{DA}$ release to the cue over iterative extinction trials (blue lines) relative to rewarded chain sessions (black line). BvCore DA release to operant responses and reward during the reinforced chain schedule (black) and early extinction (blue) aligned to the $\mathrm{TL}^{\mathrm{P}}$ event. Gray bar shows range of maximum and minimum concentrations of DA during the baseline period. $C$, Peak DA relative to the $\mathrm{SL}^{\mathrm{P}}, \mathrm{TL}^{\mathrm{P}}$, and reward in the reinforced schedule and early extinction. $\boldsymbol{D}$, Alignment to the $\mathrm{SL}^{0}$ in the shell (red lines) revealed more discrete decreases in phasic DA release to the cue over iterative extinction trials relative to rewarded chain sessions (black line). $E$, DA signaling aligned to the $\mathrm{TL}^{\mathrm{P}}$ in the shell in early extinction (red) and the reinforced chain schedule (black). $\boldsymbol{F}$, Peak DA in the shell was unchanged at $S L^{\mathrm{P}}$, but showed significant decreases at $\mathrm{TL}^{\mathrm{P}}$ and reward. ${ }^{*} p<0.05,{ }^{* *} p<0.01$, chain versus early extinction; $\nmid p<0.05$, omission less than baseline.

$p=0.04$, suggesting that the TL (perhaps by virtue of its immediate relationship with the reward) was more sensitive to reward omission than the SL. In contrast, the number of trials before making the first omission was nearly identical for both SL and TL levers $(p>0.9)$, perhaps indicating that omitted responses were only emitted when the prediction of reward had accurately updated to zero at the onset of the trial. Consistent with this, we rarely found trials where animals performed a SL ${ }^{\mathrm{P}}$ but omitted a subsequent $\mathrm{TL}^{\mathrm{P}}$ response (only 4/140 total late-phase trials; $2.9 \%$ ), suggesting that rats almost exclusively performed either the entire chain sequence or not at all. As such, omissions were likely more linked to information available at the SL than TL.

Next, we examined average latencies for the $\mathrm{SL}^{\mathrm{P}}$ and $\mathrm{TL}^{\mathrm{P}}$ in each phase based on the above criteria. A two-way repeated-measures ANOVA comparing response latency on the different levers (SL, TL) during different phases of the task (chain, early extinction, delay extinction, late press) showed a significant main effect of lever $\left(F_{(1,4)}\right.$ $=45.7, p=0.003$ ), which was due to significantly more rapid responses on the TL than the SL (Fig. 5B), consistent with performance during typical reinforced sessions, and a significant main effect of extinction phase $\left(F_{(3,12)}=14.5, p<0.001\right)$. For the SL, SL ${ }^{\mathrm{P}}$ re- sponses during early extinction were similar to those during the reinforced chain session (Tukey: $p=1.0$ ), but significantly slowed by the delay ( $p=0.02$ vs early) and late press ( $p=0.003$ vs early) phases. However, press latencies on the SL were similar between the delay and late phase $(p=0.89)$. For TL presses, response latency shifts were more subtle, with the Late phase being significantly slower than the early phase $(p=0.04)$. However, a linear contrast accounted for the greatest proportion of variance in the TL latency $\operatorname{shift}\left(F_{(1,4)}=11.08, p=0.03 ; 86 \%\right.$ of main effect variance), whereas for the SL, a contrast comparing the chain and early versus the delay and late phases accounted for the greatest proportion of the effect variance $\left(F_{(1,4)}=15.42, p=0.02 ; 97 \%\right.$ of main effect variance).

Extinction: omitted outcome differentially augments core and shell DA signaling

Event-related DA signaling in the NAc shifted as the rat progressed through the behaviorally defined phases of extinction. The manner in which DA encoding was affected by extinction strikingly varied between core and shell (Fig. 6).

We first examined DA signaling in the core during extinction. Relative to the $\mathrm{SL}^{\mathrm{O}}$, DA significantly and linearly decreased 
across the different phases of extinction relative to the rewarded chain session, (interaction: phase $\times$ cue; $\mathrm{SL}^{\mathrm{O}}$ vs baseline; $F_{(4,157)}$ $=33.19, p<0.0001$; Fig. 6 A. Post hoc pairwise comparisons showed that peak DA to the $\mathrm{SL}^{\mathrm{O}}$ rapidly decreased between the chain and early extinction phases (Tukey: $p<0.0001$ ), and again between early extinction and late extinction $(p<0.0001)$. However, DA during the delay extinction was not different from in the late press block $(p=0.64)$ and peak DA did not differ in the late phase based on whether the rat made a response or not (late press vs late no press, $p=0.99)$. Further, DA release during the $\mathrm{SL}^{\mathrm{O}}$ was significantly greater than baseline in the chain $(p<0.0001)$, early extinction $(p<0.0001)$, and delay extinction $(p<0.001)$ phases, but not in the late press or late no press phases (both $p>0.5$ ). These pairwise findings supported a significant negative linear trend $\left(F_{(1,157)}=94.77, p<0.0001\right)$, which accounted for a majority $(71 \%)$ of the effect variance.

Next, one hallmark of PE signals in the brain is the presence of negative prediction errors at the time of an omitted expected reward (Schultz et al., 1997). We anticipated that these signals would be strongest early in extinction when the subject had full expectation that the reward would be delivered. In the core (Fig. $6 B)$, a two-way ANOVA indicated a significant interaction of event $\times$ phase (chain vs early extinction; $F_{(3,57)}=3.24, p=$ 0.029 ). Specifically, although peak DA release relative to the preceding $\mathrm{SL}^{\mathrm{P}}$ was significantly reduced in early extinction relative to the reinforced chain session, (Tukey: $p=0.019$ ), DA release to the $\mathrm{TL}^{\mathrm{P}}$ was unaffected $(p=0.41)$. Critically, core DA showed evidence of a negative prediction error during extinction (Fig. $6 B$ ) such that DA release during the time of the expected but omitted reward was significantly lower than during the reinforced session $(p=0.003)$. Indeed, whereas peak DA release to the reward was no different from baseline during the reinforced Chain session ( $p=0.99)$, it shifted to significantly less than baseline during reward omissions ( $p=0.03$ ). Thus, DA signals in the core during early extinction displayed both dynamic shifts in release to predictive SL stimuli and actions, no change relative to a TL cue, and a negative prediction error to reward omission.

The shell showed a different pattern of DA release relative to the $\mathrm{SL}^{\mathrm{O}}$ cue (Fig. $6 D$ ). Here, subject-averaged cue-evoked $\mathrm{DA}$ to the $\mathrm{SL}^{\mathrm{O}}$ dynamically changed across phases, (interaction: phase $\times$ cue; $\left.F_{(2,24)}=7.95, p<0.0005\right)$, but unlike the core, shell DA did not change between the chain phase and early extinction, $(p=0.74)$, but DA signaling to the $\mathrm{SL}^{\mathrm{O}}$ was significantly decreased during the delay extinction phase relative to both the reinforced chain phase $(p=0.041)$ and the early extinction phase $(p=0.02)$, coincident with the rats' motivational shift in behavior (Fig. 5). DA signaling significantly decreased again between the delay phase and late phases (late press, $p=0.03$; late no press, $p=0.004)$, but there was no difference in DA levels between the late phases (press versus no press, $p=0.43$ ). As in the core, DA release during the $\mathrm{SL}^{\mathrm{O}}$ was significantly above baseline during the chain, early extinction and delay extinction phases (Tukey: all $p<0.001$ ), but neither of the late phases were significantly different from baseline. Thus, core DA release rapidly and continuously tracked changes in prediction for the most predictive cue, while patterns of DA release for the same cue in the shell instead tracked changes in motivational state between extinction phases.

Looking at pressing and reward signaling, shell DA release differed from the pattern in the core (Fig. 6E,F). A two-way ANOVA examining DA on individual trials by stimulus type (BL, $\mathrm{SL}^{\mathrm{P}}, \mathrm{TL}^{\mathrm{P}}$, reward) and extinction phase (chain, early extinction) found a significant interaction between stimulus $X$ extinction $\left(F_{(3,108)}=11.5, p<0.0001\right.$; Fig. $\left.6 D\right)$. Unlike the core, there was no difference in peak shell DA release to the $\mathrm{SL}^{\mathrm{P}}$ early in extinction $(p=0.44)$. Instead, extinction induced a significant decrease in DA release to both the $\mathrm{TL}^{\mathrm{P}}(p=0.01)$ and at the time of reward omission relative to reward receipt $(p<0.0001)$ relative to the matched time during the reinforced Chain schedule. During the rewarded Chain session, DA was significantly elevated above baseline $(p<0.0001)$, but during reward omission, DA was numerically greater than, but not statistically different from baseline $(p=0.07)$. Thus, unlike the core, we found limited evidence for early extinction prediction errors, and instead a decrease in DA release relative to the TL (but not SL) press as well as the elimination of DA release at the reward seen during the reinforced schedule.

\section{Discussion}

Phasic DA release patterns tracked stimuli that strikingly differed between NAc subregions in a manner consistent with contrasting theories of DA function. In a well learned chain schedule task, DA in the NAc core selectively peaked at the most predictive cue, and linearly tracked changes in prediction value and errors during extinction. In contrast, phasic DA release in the NAc shell tracked all salient stimuli when the task was rewarded, and both within session and during extinction displayed changes in signaling consistent with shifts in motivation. As such, we propose that these DA signals are simultaneously available to the animal during behavior, allowing both predictive and motivational information to guide learning and action.

\section{Core DA release tracks prediction error}

In the core, DA phasically increased at the time of SL cue presentation and declined to baseline for fully predicted later events (e.g., TL, reward), similar to previous findings (Roitman et al., 2004; Cacciapaglia et al., 2012). This pattern of activity is consistent with error prediction models, which state that maximally predictive cues should elicit the highest DA release (i.e., prediction), whereas accurately predicted events that follow should elicit minimal DA release (i.e., prediction error). Thus, as the TL and reward were predicted accurately by the SL, they generated little error at their delivery, and evoked little error-related DA release (Schultz et al., 1997; Schultz and Dickinson, 2000).

Our laboratory and others have shown that DA signals in the core are sensitive to differences in predicted value, and are modulated by subjective factors like risk preference and delays to reinforcement (Day et al., 2010; Gan et al., 2010; Sugam et al., 2012; Saddoris et al., 2013, 2015). For example, in rats performing a risky decision making task, core DA scaled with cues that predicted the rat's preferred option, and rapidly dropped below baseline when expected rewards were omitted, indicative of a negative prediction error (Sugam et al., 2012). Likewise here, core DA tracked both the value of predicted outcomes, and dynamically shifted based on the updated predicted cue value during extinction. Indeed, DA release to the $\mathrm{SL}^{\mathrm{O}}$ was no different from baseline by the time the rat began omitting responses during extinction, regardless of whether or not a response was made, suggesting DA signaled the anticipated value of responding, rather than the motivation to press. Further, reward omissions early in extinction elicited robust pauses in DA release, consistent with negative prediction error signaling.

\section{Shell DA tracks motivationally salient stimuli}

DA release in the shell discretely tracked all salient stimuli $\left(\mathrm{SL}^{\mathrm{O}}\right.$, $\left.\mathrm{TL}^{\mathrm{O}}, \mathrm{R}\right)$. These patterns could not be explained by slower reuptake kinetics, and instead appear to reflect real-time encoding 
of contingent events (Pan et al., 2005) and acquired incentive salience (Berridge and Robinson, 1998; Berridge, 2012; Wassum et al., 2012). Thus, DA release events encoded both predictive cues and rewards in the shell, but only predictive cues in the core (Cacciapaglia et al., 2012).

We found evidence for this motivational component of shell DA signaling. First, DA signaling in the shell to stimuli was decreased between the beginning and end of sessions, which was not seen in the core. One explanation is that rats in the end of the session were simply more sated (by definition, they had eaten more food than at the onset of the session), and as such, cues predictive of the food reflected the diminished motivational state of the animal. In contrast, the cues still accurately predicted the delivery of the sucrose pellet, so the PE-type encoding in the core was relatively less affected by this motivational shift.

Second, during extinction, DA release in the shell to the $\mathrm{SL}^{\mathrm{O}}$ remained stable while the rat was performing the task at the same motivational level (as indicated by response latency and accuracy), but significantly decreased after the rats' motivation declined (i.e., response latency) over the course of extinction. In contrast, we saw rapid decreases in phasic DA release during the TL stimuli. IS models predict that cues that reduce uncertainty should create greater motivation and incentive salience (Zhang et al., 2009; Smith et al., 2011), which here is biased toward the TL, as it is maximally predictive of imminent reward delivery. Indeed, intra-NAc shell infusions of amphetamine selectively potentiate the encoding of cues most proximal to the delivery of reward in a chained pavlovian task, but have less effect on the first cue in the sequence (Smith et al., 2011). Thus, DA encoding of the TL was particularly sensitive to the predicted loss of reward delivery in extinction. Surprisingly, reward omissions did not result in DA release below baseline, suggesting that shell DA was less likely to encode a negative prediction error than the core. Collectively, this pattern of signaling within the NAc shell is distinctly different from the core, and is suggestive of IS-type encoding.

In support, the NAc shell has been implicated in a variety of motivationally driven behaviors. For example salt appetite, where a salty solution is normally aversive, can be rewarding if the animal is salt-deprived. In both cases, the predicted outcome (salt) is the same, but the motivation to obtain that outcome differs between the normal and salt-deprived animals (Tindell et al., 2009). NAc neural encoding for the salty solution is modulated in the shell based on the degree of salt motivation, while core neurons failed to display state-based differences (Loriaux et al., 2011). Similarly, intra-NAc shell microinfusions of amphetamine strongly potentiates the motivational vigor of lever pressing in the presence of a cue during pavlovian-to-instrumental transfer (PIT), as does chronic pretransfer experience with cocaine (Wyvell and Berridge, 2000; Saddoris et al., 2011; LeBlanc et al., 2013). Indeed, the experience with self-administered cocaine that potentiates PIT behavior also preferentially increases NAc shell neural encoding relative to the core (Saddoris et al., 2011).

This pattern of IS and PE in the shell and core appears to track both appetitive and aversive conditions. In pavlovian fear conditioning, phasic DA increases in the NAc shell for salient aversive cues, whereas core DA release saw decreases and pauses in release indicative of PE-type prediction of a negative outcome (Badrinarayan et al., 2012). Thus, even negative (but salient) events can be accounted for with an IS-type model within the shell, whereas core DA release remains strongly coupled to predictions of outcome value.

\section{Complexity of PE and IS signaling in conditioning}

One caveat is that in pavlovian conditioning, animals that preferentially interact with predictive cues ("sign trackers") show enhanced DA release in the NAc core compared with those that immediately go to the food cup ("goal trackers"; Flagel et al., 2011). This increased sign-tracking is described as supporting IS, as the cue has become a salient stimulus capable of acting as a motivational "magnet" and accords with similar findings in the core (Aragona et al., 2009; Peciña and Berridge, 2013; Wassum et al., 2013; Ostlund et al., 2014). This appears to be at odds with our assignment of PE biased to the core and IS to the shell.

It is important to note that the respective roles of DA signal in the core and shell is likely complex. For example, few of the above studies have independently investigated the role of shell and core in these tasks, so increased DA in the core in sign-tracking animals may simply reflect a generalized increase in incentive DA signals in the mesolimbic pathway. Further, we are not advocating an absolute division; we found some DA release to the $\mathrm{TL}^{\mathrm{O}}$ in the core, although DA to the $\mathrm{SL}^{\mathrm{O}}$ in the shell persisted despite changes in motivation during extinction, suggesting that features of IS may be present in the core and PE in the shell (though at lower levels and/or less responsive to task dynamics). Rather, we suggest that core and shell represent a critical biasing toward PEand IS-type encoding patterns, which is consistent with the more graded composition of striatal anatomy (Haber, 2014).

\section{Implications for addiction}

Model-based differences in core and shell DA signaling have important implications beyond natural reward learning. For example, although drugs of abuse are initially rewarding, over time, drug-associated stimuli can induce feelings of intense aversive craving, imposing a negative affective state that drives drugseeking (Koob and Le Moal, 1997). Prolonged abstinence from drugs increases the impact of drug-associated stimuli though a process known as incubation of craving (Grimm et al., 2001; Hollander and Carelli, 2005; Pickens et al., 2011). The predicted outcome (drug) is unchanged in both the immediate and abstinent condition, but there is a profound increase in the motivation to resume drug taking in the abstinent subjects. This suggests a significant change in those stimuli's incentive salience and would predict that abstinence-related changes should preferentially be seen in the shell. Relatedly, when drug-self-administering rats are presented with cocaine-predictive cues that induce an aversive motivational state, changes in DA signaling track the aversive state of the animal in the shell but not the core (Wheeler et al., 2011). Collectively, these findings support that core and shell DA contributions to learning and motivation are consistent across both natural and drug rewards.

\section{References}

Aragona BJ, Day JJ, Roitman MF, Cleaveland NA, Wightman RM, Carelli RM (2009) Regional specificity in the real-time development of phasic dopamine transmission patterns during acquisition of a cue-cocaine association in rats. Eur J Neurosci 30:1889-1899. CrossRef Medline

Badrinarayan A, Wescott SA, Vander Weele CM, Saunders BT, Couturier BE, Maren S, Aragona BJ (2012) Aversive stimuli differentially modulate real-time dopamine transmission dynamics within the nucleus accumbens core and shell. J Neurosci 32:15779-15790. CrossRef Medline

Berridge KC (2012) From prediction error to incentive salience: mesolimbic computation of reward motivation. Eur J Neurosci 35:1124-1143. CrossRef Medline

Berridge KC, Robinson TE (1998) What is the role of dopamine in reward: hedonic impact, reward learning, or incentive salience? Brain Res Rev 28:309-369. CrossRef Medline

Bromberg-Martin ES, Matsumoto M, Hikosaka O (2010) Dopamine in mo- 
tivational control: rewarding, aversive, and alerting. Neuron 68:815-834. CrossRef Medline

Budygin EA, John CE, Mateo Y, Jones SR (2002) Lack of cocaine effect on dopamine clearance in the core and shell of the nucleus accumbens of dopamine transporter knock-out mice. J Neurosci 22:RC222. Medline

Cacciapaglia F, Saddoris MP, Wightman RM, Carelli RM (2012) Differential dopamine release dynamics in the nucleus accumbens core and shell track distinct aspects of goal-directed behavior for sucrose. Neuropharmacology 62:2050-2056. CrossRef Medline

Cohen JY, Haesler S, Vong L, Lowell BB, Uchida N (2012) Neuron-typespecific signals for reward and punishment in the ventral tegmental area. Nature 482:85-88. CrossRef Medline

Day JJ, Jones JL, Wightman RM, Carelli RM (2010) Phasic nucleus accumbens dopamine release encodes effort- and delay-related costs. Biol Psychiatry 68:306-309. CrossRef Medline

Flagel SB, Clark JJ, Robinson TE, Mayo L, Czuj A, Willuhn I, Akers CA, Clinton SM, Phillips PE, Akil H (2011) A selective role for dopamine in stimulus-reward learning. Nature 469:53-57. CrossRef Medline

Gan JO, Walton ME, Phillips PE (2010) Dissociable cost and benefit encoding of future rewards by mesolimbic dopamine. Nat Neurosci 13:25-27. CrossRef Medline

Grimm JW, Hope BT, Wise RA, Shaham Y (2001) Neuroadaptation: incubation of cocaine craving after withdrawal. Nature 412:141-142. CrossRef Medline

Haber SN (2014) The place of dopamine in the cortico-basal ganglia circuit. Neuroscience 282C:248-257. CrossRef Medline

Heien ML, Khan AS, Ariansen JL, Cheer JF, Phillips PE, Wassum KM, Wightman RM (2005) Real-time measurement of dopamine fluctuations after cocaine in the brain of behaving rats. Proc Natl Acad Sci U S A 102:1002310028. CrossRef Medline

Hollander JA, Carelli RM (2005) Abstinence from cocaine self-administration heightens neural encoding of goal-directed behaviors in the accumbens. Neuropsychopharmacology 30:1464-1474. CrossRef Medline

Jones SR, O'Dell SJ, Marshall JF, Wightman RM (1996) Functional and anatomical evidence for different dopamine dynamics in the core and shell of the nucleus accumbens in slices of rat brain. Synapse 23:224-231. CrossRef Medline

Keithley RB, Carelli RM, Wightman RM (2010) Rank estimation and the multivariate analysis of in vivo fast-scan cyclic voltammetric data. Anal Chem 82:5541-5551. CrossRef Medline

Koob GF, Le Moal M (1997) Drug abuse: hedonic homeostatic dysregulation. Science 278:52-58. CrossRef Medline

LeBlanc KH, Maidment NT, Ostlund SB (2013) Repeated cocaine exposure facilitates the expression of incentive motivation and induces habitual control in rats. PloS One 8:e61355. CrossRef Medline

Loriaux AL, Roitman JD, Roitman MF (2011) Nucleus accumbens shell, but not core, tracks motivational value of salt. J Neurophysiol 106:1537-1544. CrossRef Medline

Olmstead MC, Parkinson JA, Miles FJ, Everitt BJ, Dickinson A (2000) Cocaine-seeking by rats: regulation, reinforcement, and activation. Psychopharmacology 152:123-131. CrossRef Medline

Ostlund SB, LeBlanc KH, Kosheleff AR, Wassum KM, Maidment NT (2014) Phasic mesolimbic dopamine signaling encodes the facilitation of incentive motivation produced by repeated cocaine exposure. Neuropsychopharmacology 39:2441-2449. CrossRef Medline

Owesson-White CA, Ariansen J, Stuber GD, Cleaveland NA, Cheer JF, Wightman RM, Carelli RM (2009) Neural encoding of cocaine-seeking behavior is coincident with phasic dopamine release in the accumbens core and shell. Eur J Neurosci 30:1117-1127. CrossRef Medline

Pan WX, Schmidt R, Wickens JR, Hyland BI (2005) Dopamine cells respond to predicted events during classical conditioning: evidence for eligibility traces in the reward-learning network. J Neurosci 25:6235-6242. CrossRef Medline

Peciña S, Berridge KC (2013) Dopamine or opioid stimulation of nucleus accumbens similarly amplify cue-triggered "wanting" for reward: entire core and medial shell mapped as substrates for PIT enhancement. Eur J Neurosci 37:1529-1540. CrossRef Medline

Pickens CL, Airavaara M, Theberge F, Fanous S, Hope BT, Shaham Y (2011)
Neurobiology of the incubation of drug craving. Trends Neurosci 34:411420. CrossRef Medline

Redish AD (2004) Addiction as a computational process gone awry. Science 306:1944-1947. CrossRef Medline

Robinson TE, Berridge KC (2008) Review: the incentive sensitization theory of addiction: some current issues. Philos Trans R Soc Lond B Biol Sci 363:3137-3146. CrossRef Medline

Roitman MF, Stuber GD, Phillips PE, Wightman RM, Carelli RM (2004) Dopamine operates as a subsecond modulator of food seeking. J Neurosci 24:1265-1271. CrossRef Medline

Saddoris MP, Gallagher M, Schoenbaum G (2005) Rapid associative encoding in basolateral amygdala depends on connections with orbitofrontal cortex. Neuron 46:321-331. CrossRef Medline

Saddoris MP, Stamatakis A, Carelli RM (2011) Neural correlates of Pavlovian-to-instrumental transfer in the nucleus accumbens shell are selectively potentiated following cocaine self-administration. Eur J Neurosci 33:2274-2287. CrossRef Medline

Saddoris MP, Sugam JA, Cacciapaglia F, Carelli RM (2013) Rapid dopamine dynamics in the accumbens core and shell: learning and action. Front Biosci (Elite Ed) 5:273-288. Medline

Saddoris MP, Sugam JA, Stuber GD, Witten IB, Deisseroth K, Carelli RM (2015) Mesolimbic dopamine dynamically tracks, and is causally linked to, discrete aspects of value-based decision making. Biol Psychiatry 77: 903-911. CrossRef Medline

Schoenbaum G, Setlow B, Saddoris MP, Gallagher M (2003) Encoding predicted outcome and acquired value in orbitofrontal cortex during cue sampling depends upon input from basolateral amygdala. Neuron 39: 855-867. CrossRef Medline

Schultz W, Dickinson A (2000) Neuronal coding of prediction errors. Annu Rev Neurosci 23:473-500. CrossRef Medline

Schultz W, Dayan P, Montague PR (1997) A neural substrate of prediction and reward. Science 275:1593-1599. CrossRef Medline

Smith KS, Berridge KC, Aldridge JW (2011) Disentangling pleasure from incentive salience and learning signals in brain reward circuitry. Proc Natl Acad Sci U S A 108:E255-E264. CrossRef Medline

Sugam JA, Day JJ, Wightman RM, Carelli RM (2012) Phasic nucleus accumbens dopamine encodes risk-based decision-making behavior. Biol Psychiatry 71:199-205. CrossRef Medline

Tindell AJ, Smith KS, Berridge KC, Aldridge JW (2009) Dynamic computation of incentive salience: "wanting" what was never "liked." J Neurosci 29:12220-12228. CrossRef Medline

Tobler PN, Dickinson A, Schultz W (2003) Coding of predicted reward omission by dopamine neurons in a conditioned inhibition paradigm. J Neurosci 23:10402-10410. Medline

Waelti P, Dickinson A, Schultz W (2001) Dopamine responses comply with basic assumptions of formal learning theory. Nature 412:43-48. CrossRef Medline

Wassum KM, Ostlund SB, Maidment NT (2012) Phasic mesolimbic dopamine signaling precedes and predicts performance of a self-initiated action sequence task. Biol Psychiatry 71:846-854. CrossRef Medline

Wassum KM, Ostlund SB, Loewinger GC, Maidment NT (2013) Phasic mesolimbic dopamine release tracks reward seeking during expression of pavlovian-to-instrumental transfer. Biol Psychiatry 73:747-755. CrossRef Medline

Wheeler RA, Aragona BJ, Fuhrmann KA, Jones JL, Day JJ, Cacciapaglia F, Wightman RM, Carelli RM (2011) Cocaine cues drive opposing context-dependent shifts in reward processing and emotional state. Biol Psychiatry 69:1067-1074. CrossRef Medline

Wyvell CL, Berridge KC (2000) Intra-accumbens amphetamine increases the conditioned incentive salience of sucrose reward: enhancement of reward "wanting" without enhanced "liking" or response reinforcement. J Neurosci 20:8122-8130. Medline

Yorgason JT, España RA, Jones SR (2011) Demon voltammetry and analysis software: analysis of cocaine-induced alterations in dopamine signaling using multiple kinetic measures. J Neurosci Methods 202:158-164. CrossRef Medline

Zhang J, Berridge KC, Tindell AJ, Smith KS, Aldridge JW (2009) A neural computational model of incentive salience. PLoS Comput Biol 5:e1000437. CrossRef Medline 